\title{
Renewable Diesel Blendstocks and Biopriviliged Chemicals Distilled from Algal Biocrude Oil Converted via Hydrothermal Liquefaction
}

\author{
Wan-Ting (Grace) Chen, Zhenwei Wu, Buchun Si, Yuanhui Zhang
}

Submitted date: 15/08/2019 - Posted date: 15/08/2019

Licence: CC BY-NC-ND 4.0

Citation information: Chen, Wan-Ting (Grace); Wu, Zhenwei; Si, Buchun; Zhang, Yuanhui (2019): Renewable Diesel Blendstocks and Biopriviliged Chemicals Distilled from Algal Biocrude Oil Converted via Hydrothermal Liquefaction. ChemRxiv. Preprint.

This study aims to produce renewable diesel and biopriviliged chemicals from microalgae that can thrive in wastewater environment. Spirulina (SP) was converted into biocrude oil at $300^{\circ} \mathrm{C}$ for a 30 -minute reaction time via hydrothermal liquefaction (HTL). Next, fractional distillation was used to separate SP-derived biocrude oil into different distillates. It was found that $62 \%$ of the viscous SP-derived biocrude oil can be separated into liquids at about $270^{\circ} \mathrm{C}$ (steam temperature of the distillation). Physicochemical characterizations, including density, viscosity, acidity, elemental compositions, higher heating values and chemical compositions, were carried out with the distillates separated from SP-derived biocrude oil. These analyses showed that $15 \%$ distillates could be used as renewable diesel because they have similar heating values (43-46 MJ/kg) and carbon numbers (ranging from C8 to C18) to petroleum diesel. The Van Krevelan diagram of the distillates suggests that deoxygenation was effectively achieved by fractional distillation. In addition, GC-MS analysis indicates that some distillates contain biopriviliged chemicals like aromatics, phenols and fatty nitriles that can be used as commodity chemicals. An algal biorefinery roadmap was proposed based on the analyses of different distillates from the SP-derived biocrude oil. Finally, the fuel specification analysis was conducted with the drop-in renewable diesel, which was prepared with 10 vol.\% (HTL10) distillates and 90 vol.\% petroleum diesel. According to the fuel specification analysis, HTL10 exhibited a qualified lubricity $(<520 \mu \mathrm{m})$, acidity $(<0.3 \mathrm{mg} \mathrm{KOH} / \mathrm{g})$ and oxidation stability $(>6 \mathrm{hr})$, as well as a comparable net heat of combustion (1\% lower), ash content ( $29 \%$ lower) and viscosity (17\% lower) to those of petroleum diesel. Ultimately, it is expected that this study can provide insights for potential application of algal biocrude oil converted via HTL.

File list (2) 


\title{
Renewable Diesel Blendstocks and Biopriviliged Chemicals
}

\section{Distilled from Algal Biocrude Oil Converted via}

\section{Hydrothermal Liquefaction}

\author{
Wan-Ting Chen ${ }^{\mathrm{a}, \# *}$, Zhenwei $\mathrm{Wu}^{\mathrm{a} \#}$, Buchun $\mathrm{Si}^{\mathrm{a}, \mathrm{c}}$, Yuanhui Zhang ${ }^{\mathrm{a}, \mathrm{c}^{*}}$ \\ ${ }^{\text {a }}$ Department of Agricultural and Biological Engineering, University of Illinois at Urbana- \\ Champaign, Urbana, IL 61801, USA \\ b Department of Plastic Engineering, University of Massachusetts Lowell, Lowell, MA 01854, \\ USA

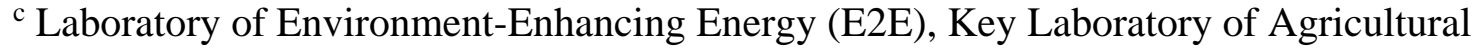 \\ Engineering in Structure and Environment, Ministry of Agriculture, College of Water Resources \\ and Civil Engineering, China Agricultural University, Beijing 100083, China \\ ${ }^{\#}$ Co-first Authors \\ *Corresponding authors.
}

WanTing_Chen@uml.edu; 185 Riverside St., Lowell, MA 01851; phone: +1-987-934-5371

YZhang1@illinois.edu; 1304 W. Pennsylvania Avenue, Urbana, IL 61801; phone: +1-217-3332693 


\begin{abstract}
This study aims to produce renewable diesel and biopriviliged chemicals from microalgae that can thrive in wastewater environment. Spirulina (SP) was converted into biocrude oil at $300^{\circ} \mathrm{C}$ for a 30-minute reaction time via hydrothermal liquefaction (HTL). Next, fractional distillation was used to separate SP-derived biocrude oil into different distillates. It was found that $62 \%$ of the viscous SP-derived biocrude oil can be separated into liquids at about $270^{\circ} \mathrm{C}$ (steam temperature of the distillation). Physicochemical characterizations, including density, viscosity, acidity, elemental compositions, higher heating values and chemical compositions, were carried out with the distillates separated from SP-derived biocrude oil. These analyses showed that $15 \%$ distillates could be used as renewable diesel because they have similar heating values (43-46 MJ/kg) and carbon numbers (ranging from C8 to C18) to petroleum diesel. The Van Krevelan diagram of the distillates suggests that deoxygenation was effectively achieved by fractional distillation. In addition, GC-MS analysis indicates that some distillates contain biopriviliged chemicals like aromatics, phenols and fatty nitriles that can be used as commodity chemicals. An algal biorefinery roadmap was proposed based on the analyses of different distillates from the SP-derived biocrude oil. Finally, the fuel specification analysis was conducted with the drop-in renewable diesel, which was prepared with 10 vol.\% (HTL10) distillates and 90 vol.\% petroleum diesel. According to the fuel specification analysis, HTL10 exhibited a qualified lubricity $(<520 \mu \mathrm{m})$, acidity $(<0.3 \mathrm{mg} \mathrm{KOH} / \mathrm{g})$ and oxidation stability $(>6$ hr), as well as a comparable net heat of combustion (1\% lower), ash content (29\% lower) and viscosity (17\% lower) to those of petroleum diesel. Ultimately, it is expected that this study can provide insights for potential application of algal biocrude oil converted via HTL.
\end{abstract}


Key Words: Biofuel; Biorefinery; Bioprivileged Chemicals; Hydrothermal Liquefaction; Algae;

Distillation 


\section{Introduction}

Microalgae are superior feedstocks for biofuels and chemicals because of their fast growth, high lipid content (20-70\%) and a relatively low environmental impact [1-3]. Most lipids from microalgae contain fatty acids. Lipids with fatty acids containing 14 to 20 carbons are suitable for biodiesel production [4]. However, due to the high water content (80-99\%) of microalgae, these energy and chemical resources have not been cost-effectively harvested at industrial scale-over $75 \%$ of the total energy input toward refinement comes from the drying process [5].

Among the current available conversions for wet biomass, hydrothermal liquefaction (HTL), involving direct liquefaction of biomass with water, has been demonstrated as an energetically favorable approach [6]. Previous studies have also proven that HTL can effectively convert wet biomass into biocrude oil, which contains closer higher heating values (HHV) to heavy crude $[3,7]$. This conversion of wet biomass to biocrude oil has been accomplished at temperatures $\left(<305^{\circ} \mathrm{C}\right)$, retention times $(15-60 \mathrm{~min})$, water contents $(70-90 \%)$, ash contents $(0$ 40\%), and various feedstock combinations [7-10].

Although HTL appears to serve as a promising method for converting wet biomass into biofuel, practical applications of biocrude oil remains as a critical bottleneck. Biocrude oil converted from wet biomass generally contains $10-20 \%$ oxygen, $3-7 \%$ nitrogen, and up to $20 \%$ moisture contents $[6-9,11]$. These impurities will result in corrosion of the engine when the biocrude oil is used as transportation fuels [12]. Further upgrading or separation of the biocrude oil is critically needed. Several previous studies have demonstrated that commercially available catalysts (e.g., zeolites, Pt/C, and Raney-Ni) had little effect on upgrading the quality of biocrude oil when the upgrading reaction temperature was below $450^{\circ} \mathrm{C}[13,14]$. On the other hand, it 
was reported that after proper separations, such as distillation, the oxygen content in the biocrude oil could be reduced to $5 \%$ and the heating values could be increased to $41-45 \mathrm{MJ} / \mathrm{kg}$ [15]. Moreover, the viscosity of the distillates separated from HTL biocrude oil was significantly reduced [16]. The reduced viscosity indicates that there is a high potential to utilize these distillates as drop-in fuels, or a blendstock for petroleum fuels [16].

A highly desirable feature of biocrude oil application in practice is to produce a blendable product (e.g., drop-in fuels) with properties that fall within international standards (e.g., ASTM guidelines), so that conventional distribution capabilities could be employed [16]. However, fuel specification analysis of algal biocrude oil were limited. As a consequence, the feasibility of algal biocrude oil as an alternative transportation fuel was unknown.

This study aims to effectively separate algal biocrude oil converted via HTL for fuel applications via fractional distillation. Spirulina platensis (SP) was used as an algal representative biomass for HTL conversion because SP can sustain in stress conditions such as nutrient deprivation environment or wastewater [3]. It is anticipated that the results from this study can provide insights to upgrade the biocrude oil converted from other kinds of algae such as mixed-culture algae from wastewater treatment plants, which has been demonstrated as a more cost-effective and sustainable algal biomass [2, 3, 7].

Physicochemical characterizations of various distillates were conducted to understand the similarity between algal biocrude oil and petroleum fuels. The density, viscosity, acidity, elemental and chemical compositions of different distillates were characterized. Results were compared to those obtained from petroleum fuels such as diesel. Selective distillates that share the closest fuel properties to petroleum diesel were used to formulate the drop-in renewable diesel, which was prepared with 10 vol.\% (HTL 10) distillates and 90 vol.\% petroleum diesel. 
Then, the fuel specification analysis was conducted with the drop-in renewable diesel (HTL 10) to evaluate their potential use as an alternative transportation fuel. In addition, the chemical composition analysis of different distillates was also used to assess the potential of using these distillates as bioprivileged molecules, which are bio-derived chemicals that can be readily converted to a variety of chemical products or used as drop-in replacements [17].

To the best of our knowledge, this present study appears to be the first of its kind to use fractional distillation to separate algal biocrude oil converted via a continuous HTL reactor and carry out a comprehensive fuel specification analysis on the distillates. With a fractional distillation, the viscosity and the impurity of algal biocrude oil are anticipated to be reduced so that the separated distillates can be used as drop-in fuels. Results from this study would expedite the downstream application of algal biocrude oil for biofuels and bioprivileged chemicals.

\section{Methods}

\subsection{Feedstock}

Spirulina platensis (SP) were purchased in dry powder form from Cyanotech (KailuaKona, $\mathrm{HI}$ ). The feedstock used in this study were all stored in a refrigerator at $4^{\circ} \mathrm{C}$ before HTL tests. The total solid content of feedstock was measured as the dry residue at $105^{\circ} \mathrm{C}$ for $24 \mathrm{~h}$. The contents of crude protein (AOAC 990.03), crude fat (AOAC 954.02), and lignin (AOAC 973.18) were measured using AOAC standard methods while acid and neutral detergent fibers were determined by Ankom Technology standard methods (MWL DF 021). Elemental analysis of feedstock was operated by a CHN analyzer (CE-440, Exeter Analytical Inc., North Chelmsford, MA) and duplicate analysis was conducted for each sample and the average value was reported. ICP analysis was employed to measure the contents of total sulfur (S), phosphorus (P), potassium $(\mathrm{K})$, magnesium $(\mathrm{Mg})$, calcium $(\mathrm{Ca})$, sodium $(\mathrm{Na})$, iron $(\mathrm{Fe})$, manganese $(\mathrm{Mn})$, copper $(\mathrm{Cu})$, and 
zinc (Zn) in the feedstocks (AOAC 985.01). Chemical and elemental compositions of SP biomass were summarized in Table 1. Results from ICP analysis were also available in Table S1 in the supplementary data.

Table 1. Chemical and elemental compositions of Spirulina used in this study

\begin{tabular}{lc}
\hline \multicolumn{1}{c}{ Compositions (d.w.\%) $^{\mathbf{a}}$} & Spirulina \\
\hline Crude protein & 64.4 \\
Crude fat & 5.1 \\
Hemicellulose & 1.4 \\
Cellulose & 0.5 \\
Lignin & 0.2 \\
Non-fiber carbohydrates $^{\mathrm{b}}$ & 18.9 \\
Ash content $_{\mathrm{C}}$ & 9.5 \\
\hline $\mathrm{C}$ & 49.3 \\
$\mathrm{H}$ & 6.4 \\
$\mathrm{~N}$ & 11.0 \\
$\mathrm{O}^{\mathrm{b}}$ & 33.3 \\
\hline
\end{tabular}

${ }^{\mathrm{a}}$ Reported by dry weight basis; ${ }^{\mathrm{b}}$ Calculated by difference (e.g., nonfibrous carbohydrate $(\%)=100$ - crude fat $(\%)$ - crude protein(\%) hemicellulose(\%) - cellulose(\%) -lignin(\%) - ash content (\%)

\subsection{Hydrothermal Liquefaction}

The HTL experiments were conducted according to the previously reported methods using a continuous stir reactor $[6,18]$. The HTL reaction was carried out at the previously determined optimum conditions for converting SP into biocrude oil $\left(300^{\circ} \mathrm{C}\right.$ and $0.5 \mathrm{~h}$ reaction time) $[6,19]$. The reactor was sealed and purged with nitrogen gas at least three times to remove the residual air in the reactor. Nitrogen gas was again added to the reactor to build a $0.69 \mathrm{MPa}$ gauge initial pressure inside the reactor to prevent water boiling during the tests. After the HTL reaction at the designated temperature and reaction time, the reactor was cooled down to approximately $60^{\circ} \mathrm{C}$ by the heat exchangers. The biocrude oil was naturally self-separated from the aqueous fraction by decanting $[18,20]$. More details were available in previous studies [18, 20]. 


\subsection{Distillation}

The distillation was conducted according to the previously reported standard methods [15, 16, 21] and the distillation curves were measured. For each distillation test, approximately $200 \mathrm{~g}$ algal biocrude oil was loaded into a $300 \mathrm{ml}$ round-bottom flask, which was heated with a stirring heating mantle (Azzota SHM-250, LabShops, Claymont, DE). To avoid quick distillations that may cause ineffective separation and safety issues, the heating rate was set at about $1^{\circ} \mathrm{C} / \mathrm{min}$. The biocrude in the flask was homogenized with a stir bar to enhance the heat transfer. In order to reduce the heat loss, glass wool was wrapped around the distillation equipment. The distillation was conducted under an atmospheric pressure. The vapor distillate was condensed by circulating tap water. Distillate fractions at a weight of $10 \mathrm{~g}$ ( 5 wt.\% of feed biocrude) each were collected at different distillation temperatures in sequence $[15,16]$. Distillation experiments were conducted for at least three independent tests and average values were reported. The distillation set-up is available in Figure S1 (supplementary data).

\subsection{Analysis of biocrude oil, distillates and distillation residues (atmospheric residue)}

Elemental compositions of biocrude oil and distillates were determined using a CE 440 elemental analyzer (Exeter Analytical). The higher heating values (HHV) of biocrude oil and distillates were calculated by using the Dulong formula based on the elemental composition: $\mathrm{HHV}=0.3383 \times \mathrm{C}+1.422 \times(\mathrm{H}-\mathrm{O} / 8)[7,9]$. The chemical compositions of distillates (extracted with hexane) were analyzed using GC-MS (Agilent Technologies). The internal standard, pentadecanoic acid methyl ester $(0.5 \mu \mathrm{M})$, was used. Detailed analytical methods were also described in previous literature $[11,16]$. Briefly, samples were analyzed using a GC-MS system consisting of an Agilent 7890 gas chromatograph, an Agilent 5975 mass selective detector, and a HP 7683B autosampler. Gas chromatography was performed on a ZB-5MS capillary column. 
The inlet and MS interface temperatures were $250^{\circ} \mathrm{C}$ and the ion source temperature was adjusted to $230^{\circ} \mathrm{C}$. The helium carrier gas was kept at a constant flow rate of $2 \mathrm{~mL} / \mathrm{min}$. The temperature program was 5 -min isothermal heating at $70^{\circ} \mathrm{C}$ followed by an oven temperature increase of $5^{\circ} \mathrm{C} / \mathrm{min}$ to $310^{\circ} \mathrm{C}$ and a final $10 \mathrm{~min}$ at $310^{\circ} \mathrm{C}$. The mass spectrometer was operated in positive electron impact (EI) mode at $69.9 \mathrm{eV}$ ionization energy at m/z 50-800 scan range. The spectra of all chromatogram peaks were compared with electron impact mass spectrum libraries (NIST08 and W8N08). To allow comparison between samples, all data were normalized to the internal standard. The instrument variability was within the standard acceptance limit (5\%).

\subsection{Drop-in fuel preparation and fuel specification analysis}

Distillates derived from SP were added into diesel to obtain a 10 vol.\% drop-in biodiesel. The fuel specifications, including viscosity, density, acidity, net heat of combustion, existent gum content, lubricity, and oxidation stability, of drop-in renewable diesel was measured and compared to those of transportation fuel standards. The characterizations of fuel specification were conducted by ASTM D 7467 standard and previously reported methods [16, 22].

\section{Results and Discussion}

\subsection{Distillation of HTL Biocrude Oil Converted from Spirulina}

After HTL, the solid phase product was defined as the biocrude oil. The elemental compositions and the heating value of the SP-derived biocrude oil are available in supplementary data (Table S2). The SP-derived biocrude oil contains heating values (26.4 MJ/kg) similar to other algal biocrude oils converted from continuous-flow reactor (25-30 MJ/kg) [23]. The SPderived biocrude oil had a high viscosity at room temperature and contained $28 \%$ oxygen contents that need to be removed to reach the same level as petroleum fuels $(<1 \mathrm{wt}$ \% oxygen 
content) [16]. This feature also makes the algal biocrude oil inappropriate to be used as drop-in fuels — diffusion of the algal biocrude oil to transportation fuel would be challenging.

Fractional distillation was then conducted to separate the SP-derived biocrude oil into several distillates. Overall, fractional distillation separated 62\% distillates and 30\% atmospheric residue from the SP-derived HTL biocrude oil (8\% was lost). As Fig.1 shows, 31\% of the distillates were first distilled at around $100^{\circ} \mathrm{C}$. Afterwards, another $31 \%$ of the distillates were distilled at $100-270^{\circ} \mathrm{C}$. This indicates that half of the distillates may be water and water-soluble compounds because they have similar boiling points as water. On the other hand, the other half of the distillates (distilled at $100-270^{\circ} \mathrm{C}$ ) may be used as fuels because they showed comparable distillation temperatures to jet fuels $\left(205-300^{\circ} \mathrm{C}\right)$ and diesel $\left(<343^{\circ} \mathrm{C}\right)[22,24]$.

Compared to the biocrude oil converted from other feedstocks (swine manure and woody biomass), fractional distillation can separate 9-20 wt.\% more distillates from SP-derived biocrude oil [16, 25, 26]. This indicates that the SP-derived biocrude oil was more volatile than the biocrude oil converted from other feedstocks. This also suggests that the biocrude oil characteristics are highly dependent on the compositions of the biomass feedstock. 


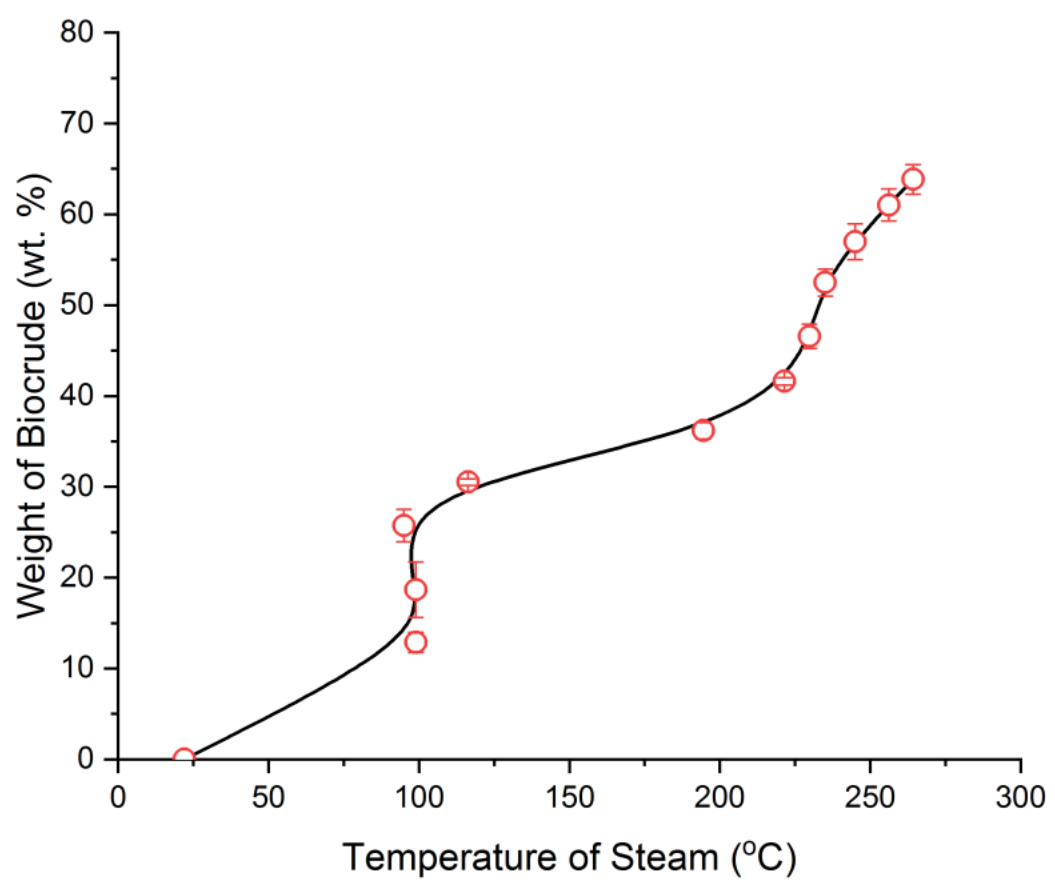

Figure 1. Distillation curves of the biocrude via HTL converted from Spirulina

\subsection{Characterization of the Distillate from SP-Derived Biocrude Oil}

\subsubsection{Density, viscosity, and acidity of different distillates}

The distillates separated from the SP-derived biocrude oil were characterized in detail to explore their potential applications. As Fig. 2 shows, the x-axis represents the steam temperature that the distillates were collected, while the y-axis displays the density, viscosity and acidity of different distillates separated from the SP-derived biocrude oil. The density of the fractions distilled before $185^{\circ} \mathrm{C}$ was close to $1 \mathrm{~g} / \mathrm{mL}$ (Fig. 2a), indicating that the first three fractions may be primarily composed of water. The density of the fractions distilled at $185-256^{\circ} \mathrm{C}(\sim 0.9 \mathrm{~g} / \mathrm{mL})$ was lighter than that of water $(1 \mathrm{~g} / \mathrm{mL})$ but heavier than jet fuel $(\sim 0.8 \mathrm{~g} / \mathrm{mL})$ and diesel $(\sim 0.85$ $\mathrm{g} / \mathrm{mL}$ ). These distillates may contain compounds heavier than petroleum fuels. For instance, the density of pyridine, a nitrogen-containing compound present in algal biocrude oil, is 0.982 $\mathrm{cm} / \mathrm{kg}^{3}$ [27], which is lighter than water but heavier than petro fuels. 
In order to confirm if the fractions distilled before $185^{\circ} \mathrm{C}$ were mainly water, another distillation apparatus (according to ASTM D95-99) was used to measure the moisture content in those distillates [28]. Because the distillates collected before $185^{\circ} \mathrm{C}$ contained $89-99$ wt.\% moisture content according to this ASTM method, their viscosity and acidity were not measured. Instead, this study focused more on the fractions distilled at $185-256^{\circ} \mathrm{C}$, which shows closer boiling point distribution and density to those of diesel and jet fuel.

Viscosity plays an important role in the fuel injection, atomization, and combustion processes [29]. Fig. $\mathbf{2 b}$ reports that the average value along with the standard deviation of the viscosity of different distillates. The viscosity of the distillates increased from $3 \mathrm{~mm}^{2} / \mathrm{s}$ to 13 $\mathrm{mm}^{2} / \mathrm{s}$ when the distillation temperature increased from $185^{\circ} \mathrm{C}$ to $256^{\circ} \mathrm{C}$. This is probably because that the amount of large molecules increased with the distillation temperature [29]. However, the viscosity of the distillates separated at $225^{\circ} \mathrm{C}$ is much higher than those separated at $219^{\circ} \mathrm{C}$ and $230^{\circ} \mathrm{C}$. This could be that the distillate separated at $225^{\circ} \mathrm{C}$ contained a high concentration of nitrogen-containing compounds such as fatty nitriles and n-heterocyclic compounds (see Table S3 in the supplementary data). In general, aliphatic and aromatic hydrocarbons have low viscosities because they have no heteroatoms (e.g., oxygen) [30]. Similar change of viscosity was also reported when distilling the biocrude oil converted from swine manure via HTL [16]. Compared to diesel and jet fuel, the distillates from SP-derived biocrude oil have a higher viscosity, possibly due to the heteroatoms (e.g., oxygen and nitrogen). The compositions of HTL distillates are generally more complex than conventional biofuels (e.g., biodiesel or bioethanol) and petro fuels [31]. Further investigation is suggested to understand if the relatively high viscosity of HTL distillates would affect the fuel injection, atomization, or combustion processes. 
Fig. 2c shows the acidity of the distillates separated at $185-256^{\circ} \mathrm{C}$. The acidity of the distillates first increased from $185^{\circ} \mathrm{C}$ to $219^{\circ} \mathrm{C}$ and then decreased from $219^{\circ} \mathrm{C}$ to $256^{\circ} \mathrm{C}$. This could be that the distillate separated at $219^{\circ} \mathrm{C}$ contained more phenols than the fractions distilled at $219-256^{\circ} \mathrm{C}$. Furthermore, the fraction distilled at $219^{\circ} \mathrm{C}$ contains less nitrogen-containing compounds to neutralize the acidity than the fraction distilled at $185^{\circ} \mathrm{C}$ (see Table S3 in the supplementary data) [32]. In contrast to the distillates separated from the biocrude oil converted from swine manure ( $\leq 80 \mathrm{mg} \mathrm{KOH} / \mathrm{g}$ ), food processing waste ( $\leq 200 \mathrm{mg} \mathrm{KOH} / \mathrm{g}$ ), and woody biomass $(\leq 71 \mathrm{mg} \mathrm{KOH} / \mathrm{g})$, the distillates from SP-derived biocrude oil has a much lower acidity ( $\leq 7 \mathrm{mg} \mathrm{KOH} / \mathrm{g}$ ) [16, 26]. This could be as a result of a higher nitrogen content and lower fatty acids in the algal biocrude oil. Although the acidity of the distillates from SP-derived biocrude oil is still higher than that of biodiesel $(\leq 0.3 \mathrm{mg} \mathrm{KOH} / \mathrm{g})$, these distillates could be readily used as a blendstock for diesel. For instance, mixing $10 \%$ of the fractions distilled at $230-256^{\circ} \mathrm{C}$ with another $90 \%$ of regular diesel (presuming no fatty acids present in petroleum diesel so the acidity is 0 ) would lead to an acidity of $0.14 \mathrm{mg} \mathrm{KOH} / \mathrm{g}$, which would meet the ASTM criteria $(\leq 0.3$ $\mathrm{mg} \mathrm{KOH} / \mathrm{g})$. 
(a)

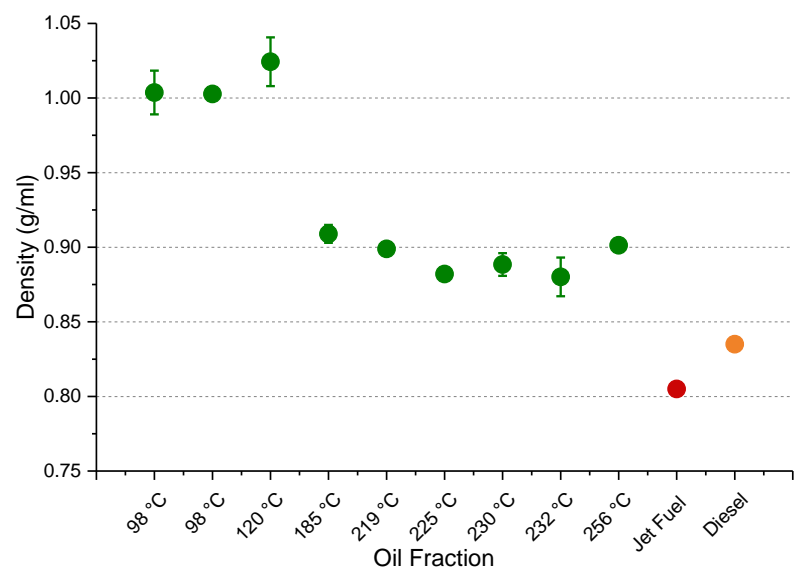

(b)

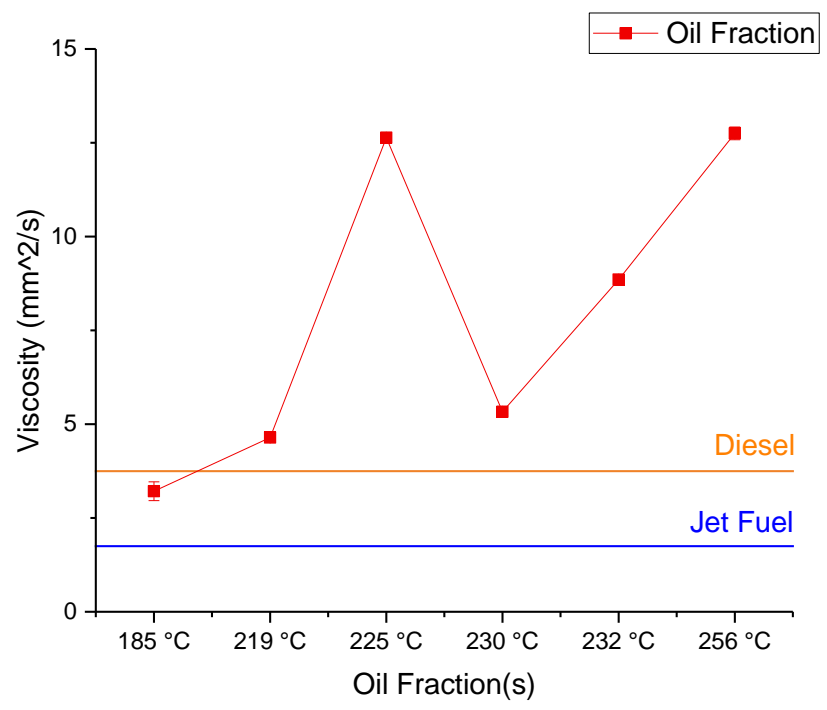

(c)

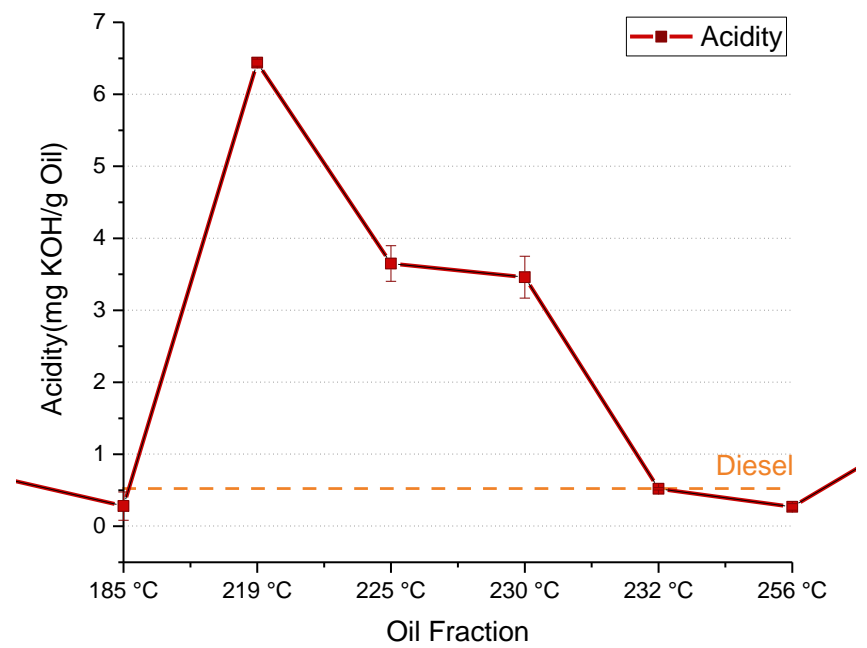

Figure 2. Physicochemical properties of SP-distillates: (a) density, (b) viscosity, and (c) acidity ( $n \geq 2)$. 


\subsubsection{Elemental compositions and HHV of different distillates}

In order to understand the carbon, hydrogen, nitrogen, oxygen, and energy contents of different distillates, the elemental compositions of the fractions distilled at $98-256^{\circ} \mathrm{C}$ and the atmospheric residue were measured. Fig. 3 displays the relationship between the distillation fractions with the elemental component (left y-axis) and the higher heating value (right y-axis). As Fig. 3 shows, the distillates collected before $185^{\circ} \mathrm{C}$ contained lower carbon but higher oxygen contents than those obtained after $185{ }^{\circ} \mathrm{C}$. This could be that the main component of the distillates collected before $185^{\circ} \mathrm{C}$ was water or water-soluble compounds, while the majority of the distillates collected after $185^{\circ} \mathrm{C}$ was hydrocarbon or nitrogen-containing compounds. In addition, the distillates separated between $185-256^{\circ} \mathrm{C}$ contained around $80 \%$ carbon, $10 \%$ hydrogen, 5-8\% nitrogen, and 2-5\% oxygen. While the carbon and hydrogen contents of the distillates kept constant, the oxygen content decreased by 57\% (from 6.1 to 2.6 wt.\%) and the nitrogen content fluctuated (ranged from 4.9-6.3 wt.\%) when the distillation temperature increased from 185 to $256^{\circ} \mathrm{C}$.

The light blue curve with square dot in Fig. 3 represents the higher heating value (HHV) of distillates. Because the distillates generated before $185^{\circ} \mathrm{C}$ contained mainly water, the $\mathrm{HHV}$ of these distillates were extremely low (around zero). On the other hand, the HHV of distillates generated after $185^{\circ} \mathrm{C}$ was in the range of $41-44 \mathrm{MJ} / \mathrm{kg}$, which equals to $89-96 \%$ energy content

of diesel (46 MJ/kg, plotted in the red dot-line in Fig. 3). About 24 wt.\% of the distillates shows a comparable HHV to that of diesel and could be suitable for transportation fuel applications. This HHV is also higher than those obtained from other upgrading methods such as catalytic hydrotreating or thermal cracking [31]. 


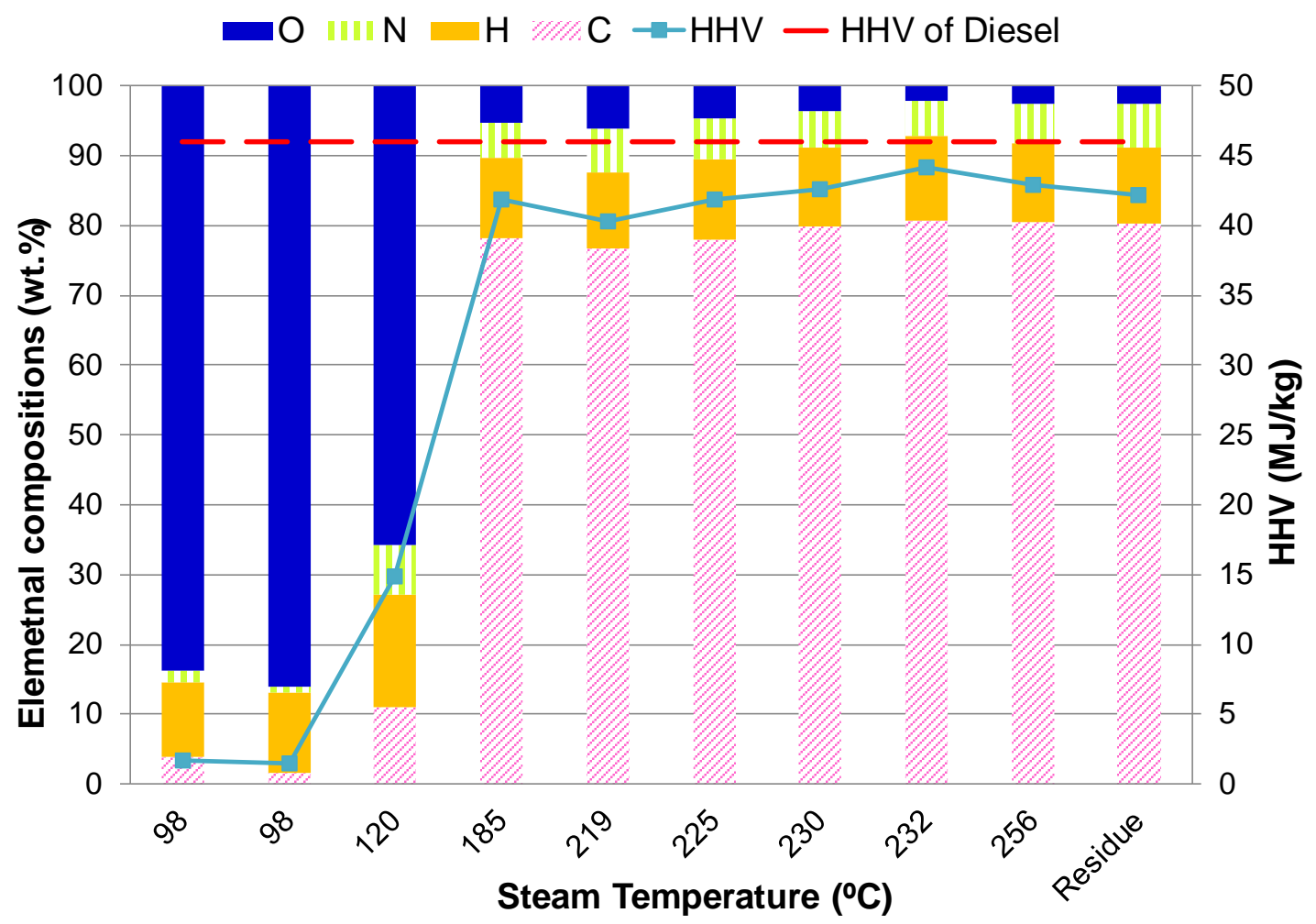

Figure 3. Elemental compositions and higher heating values (HHV) of different SPdistillates

To investigate the change of atomic ratio across distillation temperatures of $185-256^{\circ} \mathrm{C}$, the Van Krevelan diagrams were plotted in Fig. 4. The atomic ratios of transportation fuels—Jet Fuel (red dot) and Diesel (orange dot)—were also plotted for comparison. Fig. 4a cross-plots the O:C ratio as a function of the N:C ratio. The distillates can be split into two clusters. The distillates collected at $185-225^{\circ} \mathrm{C}$ had a higher O:C atomic ratio $(0.06-0.04)$ than those collected at $230-256^{\circ} \mathrm{C}(0.03-0.02)$. A $53-64 \%$ decrease in $\mathrm{O}: \mathrm{C}$ atomic ratio was observed as the distillation temperature increased from 185 to $256^{\circ} \mathrm{C}$. Furthermore, the $\mathrm{N}: \mathrm{C}$ atomic ratio decreased by $29 \%$ (from 0.07 to 0.05 ) as the distillation temperature increased from 219 to $232^{\circ} \mathrm{C}$. Deoxygenation and denitrogenation occurred when distillation temperature increased.

Fig. $\mathbf{4 b}$ cross-plots the O:C atomic ratio as a function of the $\mathrm{H}: \mathrm{C}$ ratio. Similarly, the distillates can be split into two clusters, $185-225^{\circ} \mathrm{C}$ and $230-256^{\circ} \mathrm{C}$. When the temperature 
increased, the $\mathrm{O}: \mathrm{C}$ atomic ratio decreased by $54 \%$ and the $\mathrm{H}: \mathrm{C}$ atomic ratio remained constant. Comparing to jet fuel and diesel, the distillates separated from the SP-derived biocrude oil had a lower hydrogen content. To reduce the difference, further upgrading such as hydrogenation may be required.

Overall, the Van Krevalen diagrams (Fig. 4) suggest that the fractional distillation effectively promotes deoxygenation (54\%) and denitrogenation (28\%) to the SP-derived biocrude oil. This denitrogenation efficiency was comparable to the algal biocrude oil upgraded with high pressure of hydrogen $(40 \mathrm{MPa})$ at high temperature $\left(350^{\circ} \mathrm{C}\right)$ for a long reaction time (2-4 hr) [33]. With distillation, the nitrogen content was reduced from $5 \%$ to $2-3 \%$ in the distillates. This could benefit the following upgrading steps such as catalytic denitrogenation.
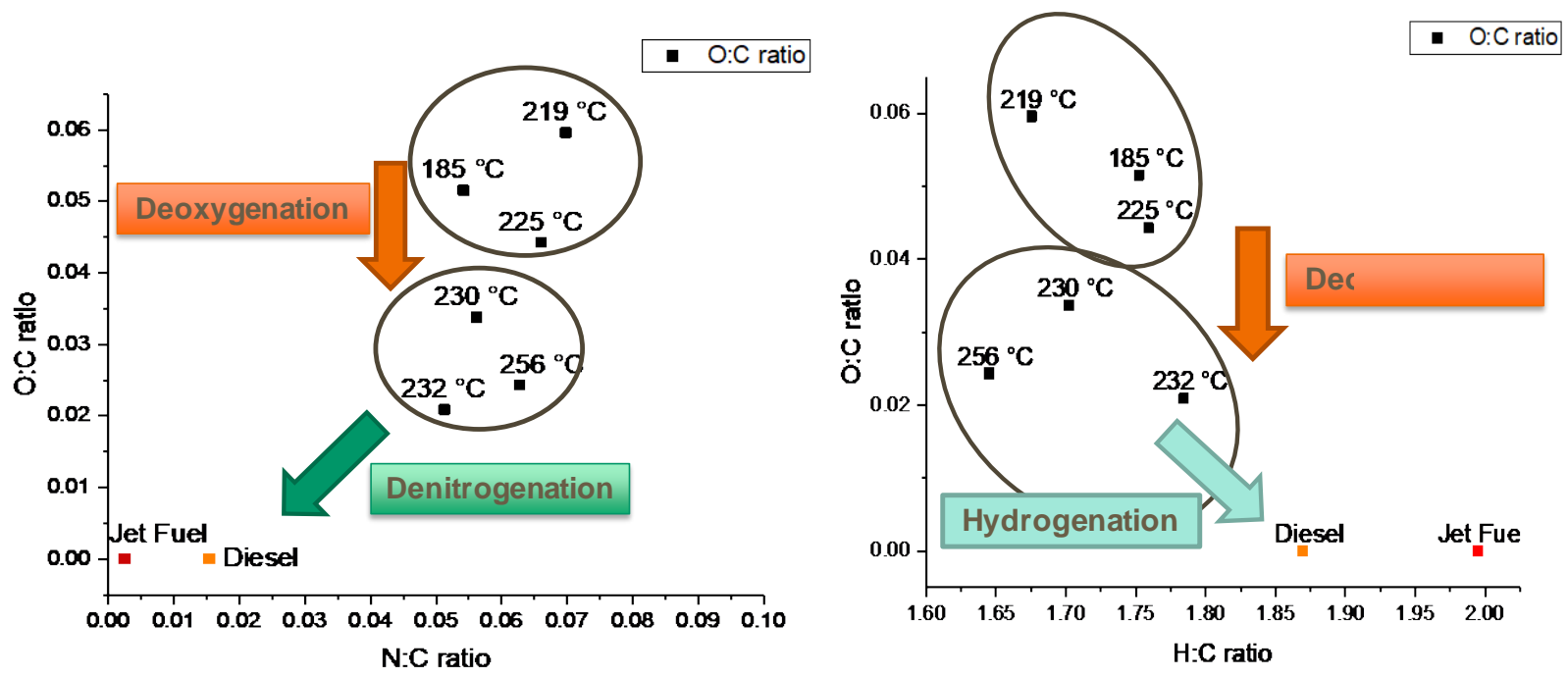

Figure 4. Van Krevelan diagram of SP-distillates: (a) O/C v.s. N/C and (b) O/C v.s. H/C atomic ratio.

\subsubsection{Chemical compositions of different distillates}

GC-MS analysis was conducted to understand how distillation temperature affects the chemical compositions of different distillates. Fig. 5 summarizes the chemical compositions of the distillates from the SP-derived biocrude. More details about the identified compounds were 
also available in supplementary data (Table S3). Components characterized by GC-MS were categorized into several major chemical groups including hydrocarbons, cyclic hydrocarbons, fatty nitriles, nitrogen-heterocyclic compounds, phenols, and amino acids. GC-MS analysis was not conducted for the fractions distilled at $98^{\circ} \mathrm{C}$ because they mainly contain water.

As Fig. 5a shows, the relative concentration of hydrocarbons increased from $120^{\circ} \mathrm{C}$ to $230^{\circ} \mathrm{C}$ and then decreased from $230^{\circ} \mathrm{C}$ to $256^{\circ} \mathrm{C}$. This indicates that the middle fractions (219$256^{\circ} \mathrm{C}$ ) of the SP-derived biocrude, which were mostly composed of straight-chain alkanes and alkenes with carbon numbers of 10-18, are more suitable for fuel application. Different from the biocrude oil converted from swine manure or food processing waste [16], the SP-derived distillates also contained branched alkanes and alkenes (e.g., tetramethylhexadecane), which is possibly converted from Chlorophyll [34]. Compared to the identifiable concentrations of hydrocarbons in biocrude oil, Fig. 5a also shows that fractional distillation can effectively separate hydrocarbons from the viscous algal biocrude oil. The concentrations of hydrocarbons were highly refined after fractional distillation. However, when the temperature increased from $230^{\circ} \mathrm{C}$ to $256^{\circ} \mathrm{C}$, the carbon numbers of hydrocarbons may increase. High-molecular weight hydrocarbons may not be distillable from algal biocrude oil and thus the concentration of hydrocarbons decreased from $230^{\circ} \mathrm{C}$ to $256^{\circ} \mathrm{C}$.

Fig. 5b summarizes the relative concentration of cyclic hydrocarbons in the distillates. It is found that the concentration of cyclic hydrocarbons peaked at $165^{\circ} \mathrm{C}$ and then decreased. The primary cyclic hydrocarbon found in the distillate separated at $165^{\circ} \mathrm{C}$ is Ionene (trimethyltetralin), which is a kind of tetralin. Tetralin is commonly used as a hydrogen-donor solvent (e.g., for coal liquefaction) and could be further refined as bioprivileged molecules that enhance the value of biomass [35]. Further quantitative analysis of the cyclic hydrocarbons is recommended for future 
research. Similar to the trend found in Fig. 5a, the concentration of cyclic hydrocarbons was significantly refined as compared to that in the biocrude oil before distillation.

Fig. 5c shows the relative concentration of fatty nitriles in the distillates. The concentration of fatty nitriles increased as the distillation temperature increased, and peaked at the highest distillation temperature, $256^{\circ} \mathrm{C}$. The major fatty nitrile identified in the distillates is hexadecanenitrile. Fatty nitrile generally is used as a precursor to synthesize fatty amines [36], which are commonly used in a variety of cosmetic applications (e.g., fabric softeners) [37]. It is worth noting that the unit price of fatty nitriles typically is higher than that of fuels, although fuels have a larger market size. Further integration of producing valuable chemicals and fuels from the same source of biomass is thereby suggested.

Fig. 5d and 5e display the relative concentration of n-heterocyclic compounds and amino acids in the distillates. The concentrations of n-heterocyclic compounds and amino acids were much lower in the distillates than in the biocrude oil. N-heterocyclic compounds and amino acids tend to partition into the aqueous phase rather than the oil phase [38]. Majority of the nheterocyclic compounds and amino acids could exist in the aqueous phase distilled at $98-120^{\circ} \mathrm{C}$.

Fig. $5 f$ illustrates the relative concentration of phenolic compounds in the distillates. The concentration of phenols increased as the distillation temperature increased from $120^{\circ} \mathrm{C}$ to $185^{\circ} \mathrm{C}$ and decreased from $185^{\circ} \mathrm{C}$ to $225^{\circ} \mathrm{C}$. Then, its concentration increased again from $225^{\circ} \mathrm{C}$ to $230^{\circ} \mathrm{C}$ and decreased from $230^{\circ} \mathrm{C}$ to $256^{\circ} \mathrm{C}$. The separation of phenol (with the boiling point of $182^{\circ} \mathrm{C}$ ) and methyl phenol (i.e., cresol) probably led to the first increase of phenols, while the second increase of phenols was possibly from the separation of dimethyl phenol (i.e., xylenol) [39]. Notably, methyl phenol has three isomers (with the boiling point range of $191-202^{\circ} \mathrm{C}$ ) and dimethyl phenol has six isomers (with the boiling point range of $203-227^{\circ} \mathrm{C}$ ) [39]. Because these 
isomers may be distilled at a wide range of temperatures, using fractional distillation to separate phenols from algal biocrude oil was ineffective. This is also reflected upon the similar concentration of phenols in the biocrude oil (before fractional distillation) and in the distillates (after fractional distillation). Other upgrading strategy is needed for the removal of phenols from HTL biocrude oil.

(a) Hydrocarbons

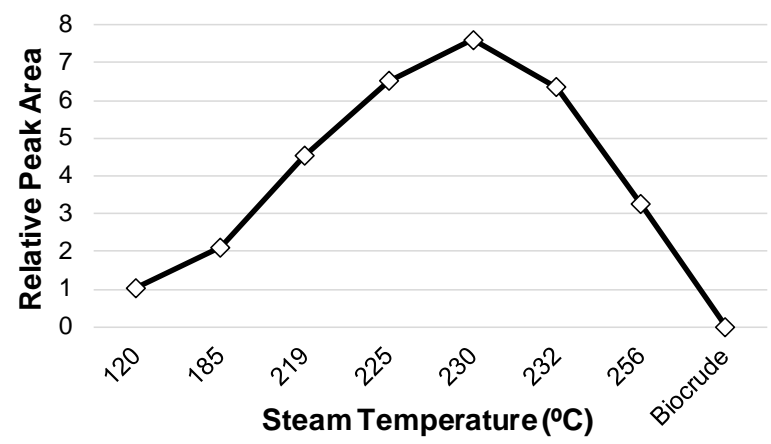

(c) Fatty Nitriles

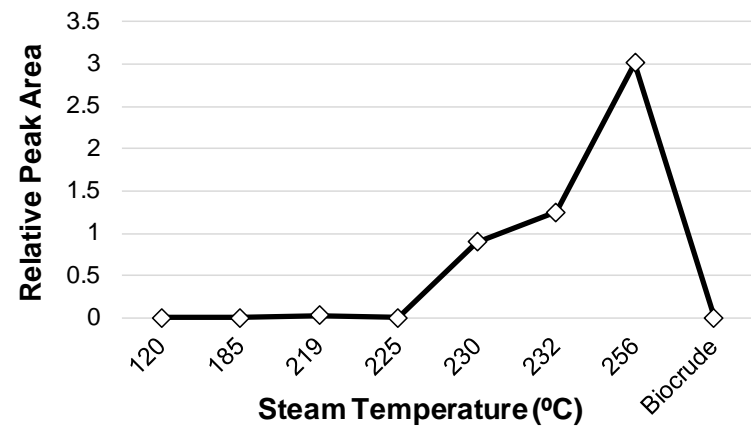

(e) Amino acids

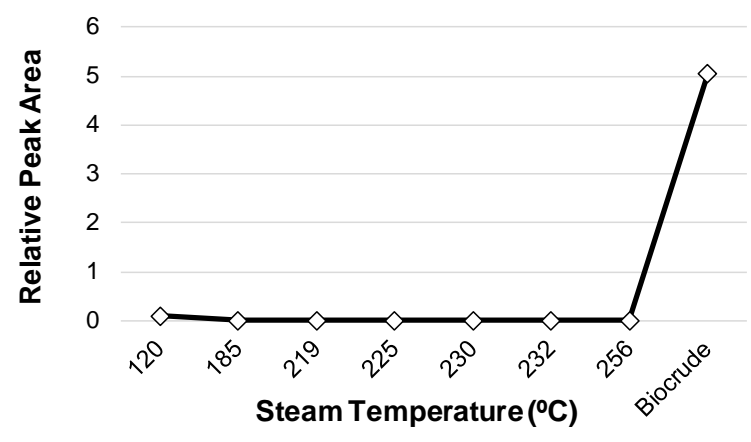

(b) Cyclic hydrocarbons

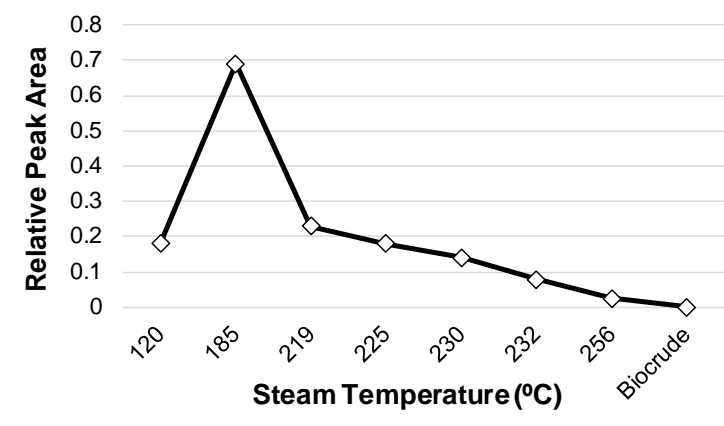

(d) N-Heterocyclic compounds

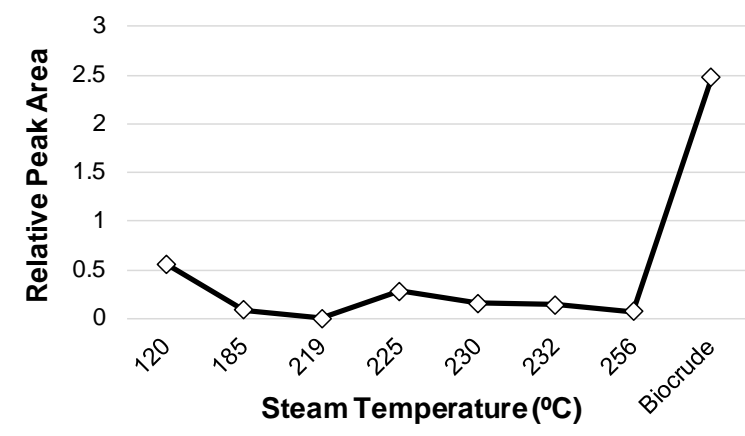

(f) Phenols

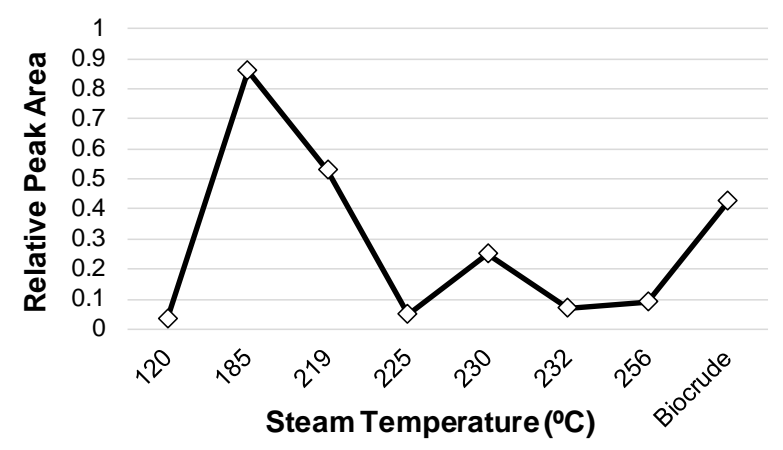

Figure 5. Chemical compositions of the SP-derived distillates obtained at different temperatures. 


\subsection{Elemental and energy recovery of biocrude oil to different distillates}

Knowing the fractional distillation yields and elemental compositions of each distillate allowed the estimation of the elemental and energy recoveries from the SP-derived biocrude oil (Fig. 6). As Fig. 6 shows, about 3\% of carbon was distributed in the first three distillates (sampled between $98-120^{\circ} \mathrm{C}$ ). Then, about $7-8 \%$ carbon was separated into each distillate separated at $185-256^{\circ} \mathrm{C}$. About $30 \%$ carbon was recovered in the atmospheric residue (the fraction denoted as $>256^{\circ} \mathrm{C}$ ), while another $24 \%$ was lost in the gas phase. During distillation, small molecules (e.g., propane and butane) could be lost because a fast and abrupt evaporation of gas vapor [40]. Similar trends was also reported with vacuum or atmospheric distillations of the pyrolytic bio-oil converted from corn stover [41]. In addition, the fractional distillation apparatus used in this study was composed of multiple pieces of glassware. When a more advanced fractional distillation apparatus (e.g., a distillation apparatus made of only one piece of glassware) is used, this lost could be reduced.

Hydrogen balance is also performed to track how much hydrogen from the SP-derived biocrude oil went to various distillates. About $47 \%$ hydrogen was recovered in the first three distillates (sampled between $98-120^{\circ} \mathrm{C}$ ). This is because that the first three distillates separated from the SP-derived biocurde oil primarily contained water and water-soluble compounds (as other characterizations demonstrated earlier). Subsequently, another 7-8\% hydrogen was recovered into each distillate separated at $185-256^{\circ} \mathrm{C}$. Another $7 \%$ hydrogen was distributed to the atmospheric residue. Only about $2 \%$ of hydrogen was lost in the gas phase. This analysis of hydrogen recovery indicates that the fractional distillation can efficiently recover the majority of hydrogen in the distillation products.

Nitrogen balance is carried out to understand how nitrogen from SP was distributed into various distillates. About 15\% nitrogen was recovered in the first three distillates (sampled 
between $98-120^{\circ} \mathrm{C}$ ). This could be that the first three distillates separated from the SP-derived biocurde oil mainly contained water-soluble compounds. Many of the nitrogen-containing compounds (e.g., amines) are water-soluble. Next, nitrogen was averagely recovered into several fractions distilled at $185-256^{\circ} \mathrm{C}(4-6 \%)$. Another $32 \%$ nitrogen was distributed into the atmospheric residue. This suggests that the atmospheric residue may contain nitrogen-doped carbonaceous material, which may be suitable for electrochemical applications with proper modification [31]. For instance, nitrogen-rich microalgae have been used to synthesized microporous carbons for electrochemical capacitors with a combination of low-cost hydrothermal carbonization and industry-adopted $\mathrm{KOH}$ activation processes [42]. Last, about $23 \%$ of nitrogen was lost in the gas phase. This is probably due to the loss of light amines. For instance, the SP-derived biocrude oil contains propylamine and butylamine that have boiling points below $80^{\circ} \mathrm{C}[38]$.

Energy recovery from the SP-derived biocrude oil to different distillates were also conducted. About $1 \%$ energy was distributed in the first two distillates (sampled between 98$99^{\circ} \mathrm{C}$ ). This is expected because the first two distillates mainly contained water. The third distillate (separated at $120^{\circ} \mathrm{C}$ ) has $5 \%$ energy recovery, as a result of the recovery of nitrogencontaining compounds and some light hydrocarbons (see more details in Table S3 in the supplementary data). Subsequently, energy was averagely recovered into the distillates separated at $185-256^{\circ} \mathrm{C}(8-9 \%)$, while another $18 \%$ energy was distributed into the atmospheric residue. Finally, about $25 \%$ of energy was lost in the gas phase, possibly due to the loss of small molecules (e.g., propane and butane) that may contain high energy contents. 


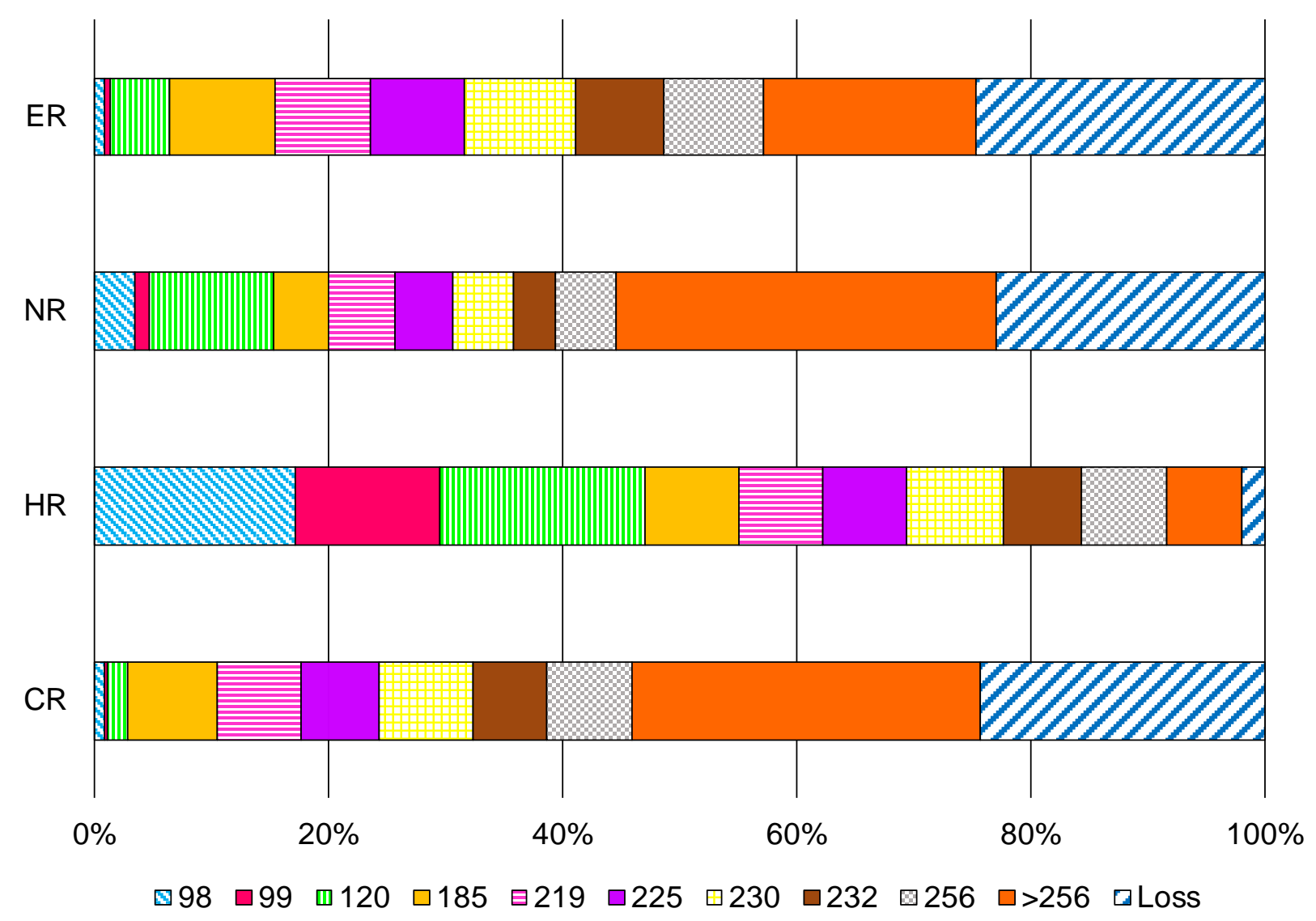

Figure 6. Elemental and energy recovery of biocrude oil to different distillates (each color block represents the element or energy recovery fractions in the distillate temperature range.)

\subsection{Fuel Specification Analysis of the Distillate from SP-Derived Biocrude Oil}

Based on the density, viscosity, acidity, elemental and chemical compositions of the distillates from SP-derived biocrude oil, the distillates separated at $185-232^{\circ} \mathrm{C}$ had the closest properties to petroleum fuels and thus were used for further fuel specification analysis. The distillates separated at $185-232^{\circ} \mathrm{C}$ were used to synthesize the drop-in renewable diesel, which was formulated with 10 vol.\% distillates and 90 vol.\% petroleum diesel (namely HTL10). Fuel specification analyses, including viscosity, acidity, net heat of combustion, existent gum content, ash content, lubricity and oxidation stability, were subjected to the drop-in renewable diesel. 
As Table 2 shows, the fuel specification of SP-HTL10 met the ASTM criteria for biodiesel application and was comparable to the performance of petroleum diesel. For instance, SP-HTL10 presents a satisfactory acidity $(0.3 \mathrm{mg} \mathrm{KOH} / \mathrm{g})$ that meets the ASTM standards [22]. This is very different as compared to those from food processing waste (FPW) or swine manure (SW) derived biocrude oil, which typically contains an excessively high acidity [16].

Existent gum contents and ash contents of the drop-in renewable diesel were also measured to investigate if additional upgrading processes are needed to remove compounds that cannot stably mix with petroleum diesel. Table 2 also demonstrates that SP-HTL 10 had a comparable performance to petroleum diesel, indicating that the SP-derived distillates can be used as stable drop-in blendstocks.

Heat of combustion is mainly affected by the elemental compositions of fuel samples [22, 24]. Compared to petroleum diesel, SP-HTL10 had a slightly lower heat of combustion. This is probably due to a higher oxygen content in SP than in petroleum diesel. Although this higher oxygen contents lead to a lower heat of combustion, they may make the drop-in renewable diesel combust more completely [43]. For instance, a recent study proves that the upgraded-FPWHTL10 and HTL20 in Table 2 can lead to a lower CO emission (primarily caused by incomplete combustion) under diesel engine combustion tests [16].

SP-HTL10 showed a superior lubricity to that of upgraded-FPW-HTL10, upgraded-FPWHTL20, and petroleum diesel. The distillates from SP-derived biocrude oil contained more fatty nitriles (e.g., heptadecanenitrile). Fatty nitriles may serve as a role of surfactants, acting as emulsifiers and dispersants in an oil-aqueous phase, and thus help improve the flowability and reduce lubricity [38]. Further rheology studies with SP-HTL10 and model compounds (e.g., 
Heptadecanenitrile with diesel) are recommended to elaborate the effect of fatty nitriles on lubricity.

It is generally believed that the oxidation stability of biodiesel links to the presence of unsaturated compounds because they tend to degrade during storage [44]. Normally, oxidation stability for biodiesel is 4-12 hours [44]. In the present work, SP-HTL10 demonstrates an oxidation stability of more than 48 hours, which suggests that there was no rapid oxidation. According to the GC-MS results (Table S3 in supplementary data), the major components in the distillates from SP-derived biocrude were alkanes. Furthermore, no fatty acids were identified in the SP-derived distillates under GC-MS.

Overall, SP-HTL 10 shows comparable fuel properties to regular diesel without any chemical modification. It is also acknowledged that the effect of the excessive nitrogen contents on fuel properties and diesel engine combustion performance remains unknown. More research with SP-HTL 10 would be needed to reveal the effect of different nitrogen-containing compounds on diesel combustion and engine performance.

Table 2. Fuel specification analysis of drop-in biodiesel (HTL10 and HTL 20 respectively represents 10 vol.\% and 20 vol.\% upgraded distillates plus 90 vol.\% petroleum diesel)

\begin{tabular}{|c|c|c|c|c|}
\hline \multirow{2}{*}{ Fuel Spec Property } & \multirow{2}{*}{$\frac{\text { SP }}{\text { HTL10 }}$} & \multicolumn{2}{|c|}{ Upgraded-FPW (adapted from [16]) } & \multirow[t]{2}{*}{ Diesel } \\
\hline & & HTL10 & HTL20 & \\
\hline Viscosity@20ㄷ $\left(\mathrm{mm}^{2} / \mathrm{s}\right)^{\mathrm{a}}$ & $3.1 \pm 0.003$ & $3.7 \pm 0.01$ & $3.1 \pm 0.02$ & $3.7 \pm 0.02$ \\
\hline Acidity (mg KOH/g) & $0.3 \pm 0.0$ & $0.1 \pm 0.004$ & $0.3 \pm 0.05$ & $0.3^{\mathrm{e}}$ \\
\hline Existent Gum (wt.\%) ${ }^{\mathrm{c}}$ & $0.55 \pm 0.03$ & $0.17 \pm 0.01$ & $0.21 \pm 0.02$ & $0.63 \pm 0.06$ \\
\hline Ash Content (wt.\%) ${ }^{\mathrm{d}}$ & $0.05 \pm 0.01$ & $\mathrm{~N} / \mathrm{A}^{\mathrm{g}}$ & $\mathrm{N} / \mathrm{A}^{\mathrm{g}}$ & $0.07 \pm 0.002$ \\
\hline Net Heat of Combustion $(\mathrm{MJ} / \mathrm{kg})^{\mathrm{f}}$ & $45.4 \pm 0.2$ & $44.7 \pm 0.3$ & $44.2 \pm 0.6$ & $46.0 \pm 0.3$ \\
\hline Lubricity $(\mu \mathrm{m})$ & 314 & 364 & 324 & $<520^{\mathrm{e}}$ \\
\hline Oxidation Stability (hrs) & $48>$ & $48>$ & $48>$ & $6>^{e}$ \\
\hline
\end{tabular}

${ }^{\mathrm{a}}$ Measured by Cannon-Fenske Viscometer (ASTM D445); ${ }^{\mathrm{b}}$ Measured by ASTM D664; ${ }^{\mathrm{C}}$ Modified by ASTM D381, heat the sample in the furnace from room temperature to $240^{\circ} \mathrm{C}$ for 60 minutes; ${ }^{\mathrm{d}}$ Measured by ASTM D482; ${ }^{\mathrm{e}}$ Adapted from ASTM D7467; ${ }^{\mathrm{f}}$ Measured by bomb Calorimeter (ASTM D4809); ${ }^{\mathrm{g}}$ Not applied because of the low existent gum contents. 


\subsection{Roadmap for Renewable Diesel and Biopriveleged Chemical Synthesized from}

\section{Microalgae}

Combining the characterization results of different distillates and potential reaction pathways reported in literature [7, 19], a roadmap for renewable fuels and biopriveleged chemical synthesized from Spirulina is proposed in Figure 7. Notably, the reaction pathways are slightly modified because the fractional distillation allows GC-MS to identify compounds that were not detectable when analyzing the biocrude oil solely. For instance, fatty nitriles and phosphate were not observed in the biocrude oil before $[10,38]$. This could be that the signals of fatty nitriles and phosphate were relatively weak compared to the main compounds in the biocrude oil [38]. Similar findings were also reported when distilling the swine manure-derived biocrude oil [16].

As Fig. 7 shows, lipids in microalgae could be hydrolyzed into fatty acids, glycerol, or phosphate under HTL. The phosphate group was probably produced from hydrolysis of phosphate ester [6]. Phosphate ester is a key component for DNA, RNA, and ATP. In addition, Spirulina may contain cyanotoxins with the chemical structure of cyclic $N$-hydroxyguanine organophosphate, given Spirulina is a kind of cyanobacteria [45]. Then, fatty acids could be converted into hydrocarbons via decarboxylation [6, 7, 19]. Hydrocarbons could be further converted into cyclic hydrocarbons or aromatics via cyclization or aromatization [46].

Proteins and carbohydrates could also be hydrolyzed into amino acids and glucose, respectively. Upon heating, Maillard reaction may occur between amino acids and reducing sugar, forming n-heterocyclic compounds (e.g., indole derivatives). Additionally, amino acids can also experience deamination and produce ammonia, which can further react with fatty acids and give fatty nitriles at high temperatures [31, 36]. Fatty nitriles are widely used as intermediate 
molecules in the chemical industries [47]. For instance, fatty nitriles are the precursor for synthesizing fatty amines, which are common surfactants and the basis for a variety of cosmetic formulations [47, 48]. Under HTL, lignin could also be degraded into phenols, which is an important industrial commodity [7]. For example, phenols are essential for production of plastics such as polycarbonates and epoxies [49].

In addition, Fig. 7 suggests that it is possible to simultaneously produce renewable fuels (diesel) and bioprivileged chemicals from the same source of biomass. In fact, it has been reported that biomass has the potential to fulfill the energy and chemical needs of society while minimizing environmental impact and increasing sustainability at the same time [50]. The petroleum industry operates on a refinery model yielding fuels and other value-added products from crude oil to maximize their economic profit. Analogously, a biorefinery is defined as "an integral unit that can accept various biological feedstocks and convert them to a range of useful products including chemicals, energy, and materials” [51]. Analysis has shown that integrating co-products with biofuels offers a substantially higher return on investment while simultaneously meeting energy and economic goals [52, 53]. For instance, as Fig. 7 shows, the price of aromatics and fatty nitriles is 2-18 times higher than that of fuels, while fuels could have a larger market size than aromatics and commodity chemicals.

However, the majority of recent research involving biomass has been focused on fuels rather than on value-added products. More research focused on producing bioprivileged chemicals that can add value to biomass is thereby advocated. 


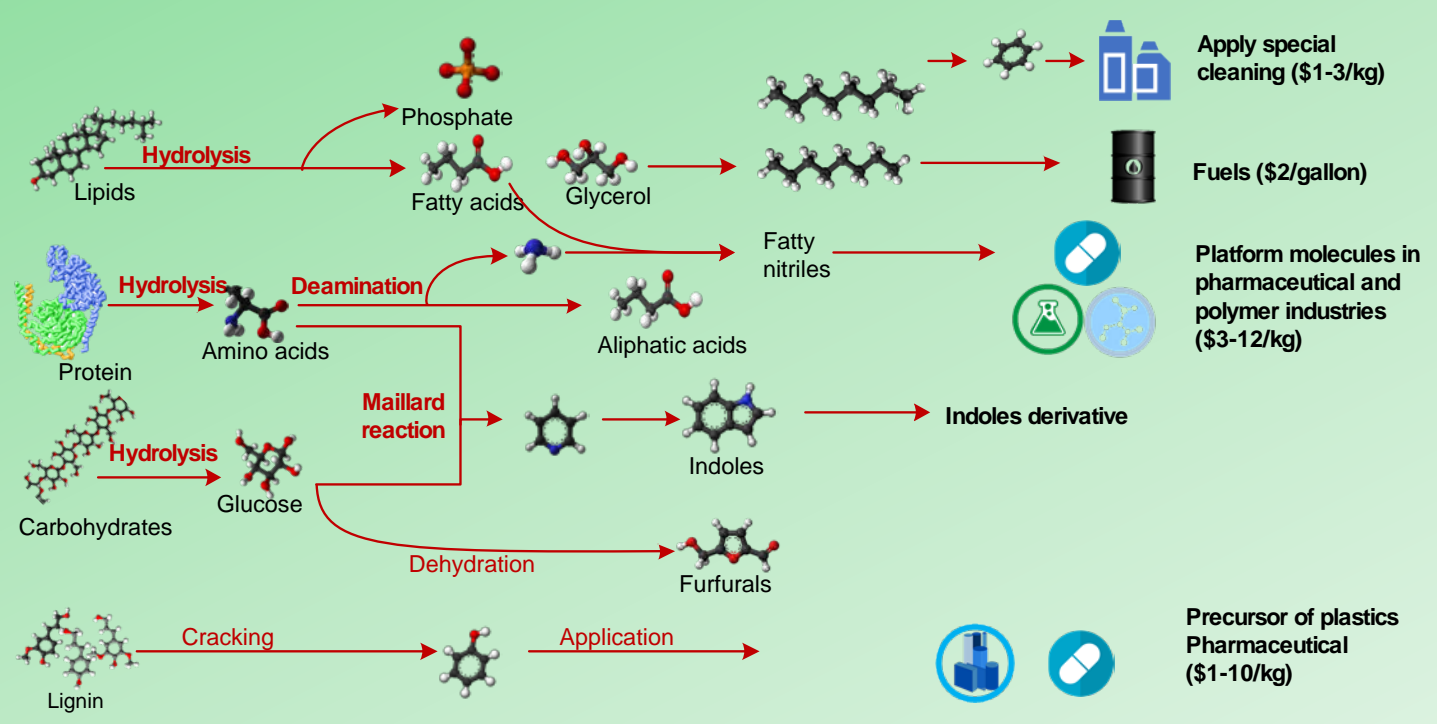

Figure 7. An algal biorefinery roadmap for producing renewable fuels and bioprivileged chemicals (the prices of fuels and chemicals are adapted from the USEIA and Alibaba.com, respectively).

\section{Conclusion}

A fractional distillation was carried out to separate the biocrude oil converted from Spirulina (SP) via hydrothermal liquefaction (HTL). It was found that the fractional distillation can separate $62 \%$ of the biocrude oil into flowable liquids at about $270^{\circ} \mathrm{C}$ (steam temperature of the distillation). The acidity of the distillates was in the range of 0 to 6 . The viscosity of these algal distillates was 3-12 mm²/s with a higher heating value (HHV) ranged from $39-44 \mathrm{MJ} / \mathrm{kg}$. Compared to the fuel and chemical properties of petroleum fuels, about $15 \%$ of the algal distillates was suitable for fuel applications. The elemental composition analysis also shows that deoxygenation of algal biocrude oil was effectively achieved by fractional distillation. In addition, chemical composition analysis indicates that some distillates contained biopriviliged chemicals like aromatics, phenols and fatty nitriles that can be used as commodity chemicals. Finally, the fuel specification analysis was conducted with the drop-in renewable diesel 
(formulated with 10 vol.\% distillates and 90 vol.\% petroleum diesel, HTL10). According to the fuel specification analysis, HTL10 exhibited a qualified lubricity $(<520 \mu \mathrm{m})$, acidity $(<0.3 \mathrm{mg}$ $\mathrm{KOH} / \mathrm{g}$ ) and oxidation stability ( $>6 \mathrm{~h}$ ), as well as a comparable net heat of combustion (1\% lower), ash content (29\% lower) and viscosity (17\% lower) to those of petroleum diesel. Ultimately, it is expected that results from this study can help understand algal biofuel properties as well as provide insights for future biorefinery of HTL algal biocrude oil.

\section{Data Availability}

The data that support the findings of this study are available from the corresponding author upon request.

\section{Corresponding Author}

Correspondence and requests for materials should be addressed to Prof. Wan-Ting Chen (WanTing_Chen@uml.edu) and Prof. Yuanhui Zhang (yzhang1@illinois.edu).

\section{Acknowledgement}

The authors thank USDA and the Snap Shot Energy Gift Fund for providing experimental supplies for the research. The first author appreciates the financial support from the University of Massachusetts Lowell and the Graduate College of University of Illinois. The authors thank Elizabeth Eves in the Microanalysis Laboratory (Urbana, IL) for their help on elemental analyses. We also greatly appreciate Dr. Alexander Ulanov of the Roy J. Carver Biotechnology Center (Urbana, IL) for his help and discussion on GC-MS analysis.

\section{Competing interests}

The authors declare no competing interests. 


\section{Reference:}

[1] Ahmad AL, Yasin NHM, Derek CJC, Lim JK. Microalgae as a sustainable energy source for biodiesel production: A review. Renewable and Sustainable Energy Reviews. 2011;15:584-93.

[2] Clarens AF, Resurreccion EP, White MA, Colosi LM. Environmental Life Cycle Comparison of Algae to Other Bioenergy Feedstocks. Environmental Science \& Technology. 2010;44:1813-9.

[3] Zhou Y, Schideman L, Yu G, Zhang Y. A synergistic combination of algal wastewater treatment and hydrothermal biofuel production maximized by nutrient and carbon recycling. Energy \& Environmental Science. 2013;6: 3765-79.

[4] Yen HW, Hu IC, Chen CY, Ho SH, Lee DJ, Chang JS. Microalgae-based biorefinery--from biofuels to natural products. Bioresource technology. 2013;135:166-74.

[5] Vasudevan V, Stratton RW, Pearlson MN, Jersey GR, Beyene AG, Weissman JC, et al.

Environmental performance of algal biofuel technology options. Environmental science \& technology. 2012;46:2451-9.

[6] Yu G. Hydrothermal liquefaction of low-lipid microalgae to produce bio-crude oil, PhD Dissertation. [PhD Dissertation]. Urbana, IL: University of Illinois at Urbana-Champaign; 2012.

[7] Chen W-T, Zhang Y, Zhang J, Yu G, Schideman LC, Zhang P, et al. Hydrothermal liquefaction of mixed-culture algal biomass from wastewater treatment system into bio-crude oil. Bioresource Technology. 2014;152:130-9.

[8] Gai C, Zhang Y, Chen W-T, Zhang P, Dong Y. Energy and nutrient recovery efficiencies in biocrude oil produced via hydrothermal liquefaction of Chlorella pyrenoidosa. RSC Advances. 2014;4:16958-67.

[9] Chen W-T, Zhang Y, Zhang J, Schideman L, Yu G, Zhang P, et al. Co-liquefaction of swine manure and mixed-culture algal biomass from a wastewater treatment system to produce bio-crude oil. Applied Energy. 2014;128:209-16.

[10] Chen W-T, Qian W, Zhang Y, Mazur Z, Kuo C-T, Scheppe K, et al. Effect of ash on hydrothermal liquefaction of high-ash content algal biomass. Algal Research. 2017;25:297-306.

[11] Yu G, Zhang YH, Schideman L, Funk T, Wang ZC. Distributions of carbon and nitrogen in the products from hydrothermal liquefaction of low-lipid microalgae. Energy \& Environmental Science. 2011;4:4587-95.

[12] Chiaramonti D, Bonini M, Fratini E, Tondi G, Gartner K, Bridgwater A, et al. Development of emulsions from biomass pyrolysis liquid and diesel and their use in engines-Part 1: emulsion production. Biomass and Bioenergy. 2003;25:85-99.

[13] Yu G, Zhang Y, Guo B, Funk T, Schideman L. Nutrient Flows and Quality of Bio-crude Oil Produced via Catalytic Hydrothermal Liquefaction of Low-Lipid Microalgae. BioEnergy Research. 2014:1-12.

[14] Zhang J, Chen W-T, Zhang P, Luo Z, Zhang Y. Hydrothermal liquefaction of Chlorella pyrenoidosa in sub- and supercritical ethanol with heterogeneous catalysts. Bioresource Technology. 2013;133:389-97. [15] Cheng D, Wang L, Shahbazi A, Xiu S, Zhang B. Characterization of the physical and chemical properties of the distillate fractions of crude bio-oil produced by the glycerol-assisted liquefaction of swine manure. Fuel. 2014;130:251-6.

[16] Chen W-T, Zhang Y, Lee TH, Wu Z, Si B, Lee C-FF, et al. Renewable diesel blendstocks produced by hydrothermal liquefaction of wet biowaste. Nature Sustainability. 2018;1:702-10.

[17] Shanks BH, Broadbelt LJ. A Robust Strategy for Sustainable Organic Chemicals Utilizing Bioprivileged Molecules.0.

[18] Ocfemia K, Zhang Y, Funk T. Hydrothermal processing of swine manure into oil using a continuous reactor system: Development and testing. Transactions of the ASAE. 2006;49:533.

[19] Gai C, Zhang Y, Chen W-T, Zhang P, Dong Y. An investigation of reaction pathways of hydrothermal liquefaction using Chlorella pyrenoidosa and Spirulina platensis. Energy Conversion and Management. 2015;96:330-9. 
[20] Ocfemia K, Zhang Y, Funk T. Hydrothermal processing of swine manure to oil using a continuous reactor system: Effects of operating parameters on oil yield and quality. Trans ASABE. 2006;49:1897904.

[21] ASTM. ASTM D86-15, Standard Test Method for Distillation of Petroleum Products and Liquid Fuels at Atmospheric Pressure. Annual Book of ASTM Standards. 2015.

[22] ASTM. ASTM D7467: Standard Specification for Diesel Fuel Oil, Biodiesel Blend (B6 to B20). Annual Book of ASTM Standards. 2015.

[23] Elliott DC, Biller P, Ross AB, Schmidt AJ, Jones SB. Hydrothermal liquefaction of biomass: developments from batch to continuous process. Bioresource technology. 2015;178:147-56.

[24] ASTM. ASTM D7566 Standard Specification for Aviation Turbine Fuel Containing Synthesized Hydrocarbons. Annual Book of ASTM Standards. 2015.

[25] Hoffmann J, Jensen CU, Rosendahl LA. Co-processing potential of HTL bio-crude at petroleum refineries - Part 1: Fractional distillation and characterization. Fuel. 2016;165:526-35.

[26] Pedersen TH, Jensen CU, Sandström L, Rosendahl LA. Full characterization of compounds obtained from fractional distillation and upgrading of a HTL biocrude. Applied Energy. 2017;202:408-19.

[27] Baysinger G. CRC Handbook of Chemistry and Physics: National Institute of Standards and Technology; 2014.

[28] ASTM. ASTM D95-99:Standard test method for water in petroleum products and bituminous materials by distillation. Annual Book of ASTM Standards. 2004.

[29] Lu Q, Li W-Z, Zhu X-F. Overview of fuel properties of biomass fast pyrolysis oils. Energy conversion and management. 2009;50:1376-83.

[30] Knothe G, Steidley KR. Kinematic viscosity of biodiesel fuel components and related compounds. Influence of compound structure and comparison to petrodiesel fuel components. Fuel. 2005;84:1059-65. [31] Chen W-T. Upgrading hydrothermal liquefaction biocrude oil from wet biowaste into transportation fuel: University of Illinois at Urbana-Champaign; 2017.

[32] Foote CS, Brown WH, Iverson BL, Anslyn EV. Organic Chemistry. Pacific Grove, CA: Brooks/Cole Publishing Company; 2011.

[33] Haider MS, Castello D, Michalski KM, Pedersen TH, Rosendahl LA. Catalytic Hydrotreatment of Microalgae Biocrude from Continuous Hydrothermal Liquefaction: Heteroatom Removal and Their Distribution in Distillation Cuts. 2018;11:3360.

[34] Warneck P. Chemistry of the Natural Atmosphere: Elsevier Science; 1999.

[35] Alemán-Vázquez LO, Domínguez JLC, García-Gutiérrez JL. Effect of Tetralin, Decalin and

Naphthalene as Hydrogen Donors in the Upgrading of Heavy Oils. Procedia Engineering. 2012;42:532-9.

[36] Foley P, Kermanshahi pour A, Beach ES, Zimmerman JB. Derivation and synthesis of renewable

surfactants. Chemical Society Reviews. 2012;41:1499-518.

[37] Amines, Aliphatic. Ullmann's Encyclopedia of Industrial Chemistry.

[38] Chen W-T, Tang L, Qian W, Scheppe K, Nair K, Wu Z, et al. Extract Nitrogen-Containing

Compounds in Biocrude Oil Converted from Wet Biowaste via Hydrothermal Liquefaction. ACS

Sustainable Chemistry \& Engineering. 2016.

[39] Organizations CSIfI.

[40] Nam H, Choi J, Capareda SC. Comparative study of vacuum and fractional distillation using pyrolytic microalgae (Nannochloropsis oculata) bio-oil. Algal Research. 2016;17:87-96.

[41] Capunitan JA, Capareda SC. Characterization and separation of corn stover bio-oil by fractional distillation. Fuel. 2013;112:60-73.

[42] Sevilla M, Gu W, Falco C, Titirici M, Fuertes A, Yushin G. Hydrothermal synthesis of microalgaederived microporous carbons for electrochemical capacitors. Journal of Power Sources. 2014;267:26-32. [43] Lee TH, Yang Z, Li G, Chen W-T, Zhang Y, Lee T, et al. Combustion Characteristics in a Constant Volume Chamber of Diesel Blended with HTL. SAE International; 2019.

[44] Kumar N. Oxidative stability of biodiesel: Causes, effects and prevention. Fuel. 2017;190:328-50. [45] Roy-Lachapelle A, Solliec M, Bouchard MF, Sauvé S. Detection of Cyanotoxins in Algae Dietary Supplements. 2017;9:76. 
[46] Chen W-T, Jin K, Linda Wang N-H. Use of Supercritical Water for the Liquefaction of Polypropylene into Oil. ACS Sustainable Chemistry \& Engineering. 2019.

[47] Shirazi Y, Tafazolian H, Viamajala S, Varanasi S, Song Z, Heben MJ. High-Yield Production of

Fatty Nitriles by One-Step Vapor-Phase Thermocatalysis of Triglycerides. ACS Omega. 2017;2:9013-20.

[48] Amines, Aliphatic. Ullmann's Encyclopedia of Industrial Chemistry. p. 1-55.

[49] Phenol. Ullmann's Encyclopedia of Industrial Chemistry.

[50] Bridgwater AV. Renewable fuels and chemicals by thermal processing of biomass. Chemical

Engineering Journal. 2003;91:87-102.

[51] Clark JH, Budarin V, Deswarte FEI, Hardy JJE, Kerton FM, Hunt AJ, et al. Green chemistry and the biorefinery: a partnership for a sustainable future. Green Chemistry. 2006;8:853.

[52] Bozell JJ. Feedstocks for the Future - Biorefinery Production of Chemicals from Renewable Carbon. CLEAN - Soil, Air, Water. 2008;36:641-7.

[53] Posada JA, Rincón LE, Cardona CA. Design and analysis of biorefineries based on raw glycerol:

Addressing the glycerol problem. Bioresource Technology. 2012;111:282-93. 


\title{
Renewable Diesel Blendstocks and Biopriviliged Chemicals
}

\section{Distilled from Algal Biocrude Oil Converted via}

\section{Hydrothermal Liquefaction}

\author{
Wan-Ting Chen ${ }^{\mathrm{a}, \mathrm{\# *}, \text { Zhenwei Wu }}{ }^{\mathrm{a} \#}$, Yuanhui Zhang ${ }^{\mathrm{a}, \mathrm{c}^{*}}$, Buchun $\mathrm{Si}^{\mathrm{a}, \mathrm{c}}$ \\ ${ }^{a}$ Department of Agricultural and Biological Engineering, University of Illinois at Urbana- \\ Champaign, Urbana, IL 61801, USA \\ ${ }^{b}$ Department of Plastic Engineering, University of Massachusetts Lowell, Lowell, MA 01854, \\ USA \\ ${ }^{c}$ Laboratory of Environment-Enhancing Energy (E2E), Key Laboratory of Agricultural \\ Engineering in Structure and Environment, Ministry of Agriculture, College of Water Resources \\ and Civil Engineering, China Agricultural University, Beijing 100083, China \\ ${ }^{\#}$ Co-first Authors \\ *Corresponding authors.
}

WanTing_Chen@uml.edu; 185 Riverside St., Lowell, MA 01851; phone: +1-987-934-5371

YZhang1@illinois.edu; 1304 W. Pennsylvania Avenue, Urbana, IL 61801; phone: +1-217-3332693 


\section{Supplementary Tables}

Table S1. Chemical and elemental compositions of Spirulina used in this study

\begin{tabular}{lc}
\hline \multicolumn{1}{c}{ Compositions $(\mathbf{d} . w . \%)^{\mathbf{a}}$} & Spirulina \\
\hline $\mathrm{S}$ & 0.73 \\
$\mathrm{P}$ & 1.06 \\
$\mathrm{~K}$ & 1.71 \\
$\mathrm{Mg}$ & 0.47 \\
$\mathrm{Ca}$ & 0.18 \\
$\mathrm{Na}$ & 1.25 \\
$\mathrm{Fe}$ & 0.02 \\
$\mathrm{Mn}(\mathrm{ppm})$ & 75 \\
$\mathrm{Cu}(\mathrm{ppm})$ & 6 \\
$\mathrm{Zn}(\mathrm{ppm})$ & 29 \\
\hline
\end{tabular}

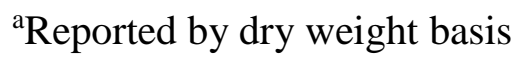

Table S2. Properties of the biocrude converted from Spirulina (dry weight basis)

\begin{tabular}{ll}
\hline Property & SP-Biocrude \\
\hline HHV (MJ/kg) & 26.4 \\
$\mathrm{C}($ wt. \%) & $58.3 \pm 0.2$ \\
$\mathrm{H}($ wt. \%) & $8.12 \pm 0.3$ \\
$\mathrm{~N}($ wt. $\%)$ & $6.00 \pm 0.2$ \\
$\mathrm{O}^{\mathrm{a}}($ wt. $\%)$ & 27.6 \\
\hline${ }^{\mathrm{a} C}$ Calculated by difference &
\end{tabular}


Table S3. Normalized GC-MS signals of major components identified in the distillates from SP-derived biocrude; " $\times$ " indicates the chemical was not detected.

\begin{tabular}{|c|c|c|c|c|c|c|c|}
\hline \multirow{2}{*}{ Compound Name } & \multicolumn{7}{|c|}{ Distillation Fractions } \\
\hline & 120 & 185 & 219 & 225 & 230 & 232 & 256 \\
\hline \multicolumn{8}{|l|}{ Hydrocarbons } \\
\hline Decane & $x$ & 0.06 & 0.17 & 0.06 & 0.12 & 0.18 & 0.11 \\
\hline Decene & $x$ & 0.02 & 0.07 & 0.01 & 0.04 & 0.10 & 0.15 \\
\hline Methyldecane & $x$ & $x$ & $x$ & $x$ & 0.02 & 0.02 & 0.01 \\
\hline Undecane & 0.03 & 0.08 & 0.20 & 0.08 & 0.18 & 0.24 & 0.13 \\
\hline Undecene & $x$ & 0.01 & 0.14 & 0.01 & 0.09 & 0.13 & 0.18 \\
\hline Demethylundecane & $x$ & 0.03 & 0.05 & 0.04 & 0.03 & 0.03 & 0.03 \\
\hline Dodecane & 0.02 & 0.09 & 0.26 & 0.12 & 0.24 & 0.30 & 0.15 \\
\hline Dodecene & 0.05 & 0.09 & 0.28 & 0.23 & 0.44 & 0.49 & 0.47 \\
\hline Trimethyldodecane & $x$ & 0.02 & 0.06 & 0.05 & 0.06 & 0.02 & 0.02 \\
\hline Tridecane & 0.03 & 0.15 & 0.36 & 0.25 & 0.40 & 0.39 & 0.20 \\
\hline Tridecene & 0.01 & $x$ & 0.12 & 0.05 & 0.15 & 0.20 & 0.18 \\
\hline Methyltridecane & $x$ & $x$ & 0.03 & 0.02 & 0.02 & 0.03 & 0.02 \\
\hline Tetradecane & $x$ & 0.21 & 0.41 & 0.50 & 0.64 & 0.53 & 0.25 \\
\hline Tetradecene & $x$ & 0.03 & 0.07 & 0.09 & 0.10 & 0.10 & 0.06 \\
\hline Pentadecane & 0.07 & 0.44 & 0.75 & 1.47 & 1.36 & 0.86 & 0.34 \\
\hline Pentadecene & $x$ & 0.05 & 0.09 & 0.18 & 0.26 & 0.23 & 0.17 \\
\hline Tetramethylpentadecane & $x$ & 0.01 & 0.03 & 0.13 & 0.15 & 0.07 & $x$ \\
\hline Hexadecane & 0.04 & 0.08 & 0.14 & 0.39 & 0.56 & 0.45 & 0.17 \\
\hline Hexadecene & 0.01 & $x$ & 0.03 & 0.16 & 0.29 & 0.34 & 0.18 \\
\hline Tetramethylhexadecane & 0.01 & 0.03 & 0.15 & 0.71 & 0.96 & 0.67 & 0.14 \\
\hline Tetramethylhexadecene & 0.21 & 0.11 & 0.17 & 0.24 & 0.07 & 0.03 & $x$ \\
\hline Heptadecane & 0.52 & 0.59 & 0.93 & 1.58 & 1.10 & 0.59 & 0.21 \\
\hline Tetramethylheptadecane & $x$ & $x$ & $x$ & $x$ & 0.09 & 0.07 & 0.05 \\
\hline Octadecane & $x$ & $x$ & $x$ & 0.06 & 0.17 & 0.23 & 0.04 \\
\hline \multicolumn{8}{|l|}{ Cycloalkanes } \\
\hline Cumene & 0.04 & 0.05 & $x$ & 0.03 & 0.02 & $x$ & $x$ \\
\hline Ionene & 0.14 & 0.48 & 0.19 & 0.07 & 0.06 & 0.03 & 0.01 \\
\hline Dimethylnaphthalene & $\times$ & $\times$ & 0.04 & 0.04 & 0.03 & 0.02 & 0.02 \\
\hline \multicolumn{8}{|l|}{ Phenols } \\
\hline Phenol & $x$ & 0.50 & $x$ & 0.02 & $\bar{x}$ & $x$ & 0.02 \\
\hline Methyl phenol & $x$ & 0.31 & 0.26 & 0.03 & 0.08 & $x$ & 0.01 \\
\hline Dimethylphenol & $x$ & $x$ & 0.13 & $x$ & 0.08 & 0.03 & 0.03 \\
\hline \multicolumn{8}{|l|}{ Oxygenates } \\
\hline Diethylene glycol dibenzoate & 0.08 & 0.11 & 0.09 & 0.11 & 0.13 & 0.13 & 0.13 \\
\hline Hexadecacenol & $x$ & $x$ & $\times$ & 0.07 & 0.10 & 0.02 & $\times$ \\
\hline \multicolumn{8}{|l|}{ N-Heterocyclic Compounds } \\
\hline Methyl indole & $x$ & $x$ & $x$ & 0.27 & 0.07 & 0.06 & $x$ \\
\hline Indolizine, 2-methyl-6-ethyl- & $x$ & $x$ & $x$ & $x$ & 0.09 & 0.08 & $\times$ \\
\hline Pyrazine, 3-ethyl-2,5-dimethyl- & 0.13 & $x$ & $x$ & $x$ & $x$ & $x$ & $x$ \\
\hline Pyrazine, ethyl-methyl & 0.14 & $\times$ & $x$ & $x$ & $x$ & $x$ & $x$ \\
\hline 1H-Pyrrole, 3-ethyl-2,4-dimethyl- & 0.03 & 0.02 & $x$ & $x$ & $x$ & $x$ & $x$ \\
\hline 1-Butyl-1H-Pyrrole & 0.06 & 0.05 & $x$ & 0.01 & $x$ & $x$ & $\times$ \\
\hline \multicolumn{8}{|l|}{ Fatty Nitriles } \\
\hline Hexadecanenitrile & 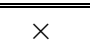 & $\bar{x}$ & $\bar{x}$ & $\bar{x}$ & 0.86 & 1.21 & 2.60 \\
\hline Heptadecanenitrile & $x$ & $x$ & $x$ & $x$ & 0.04 & 0.04 & 0.13 \\
\hline
\end{tabular}




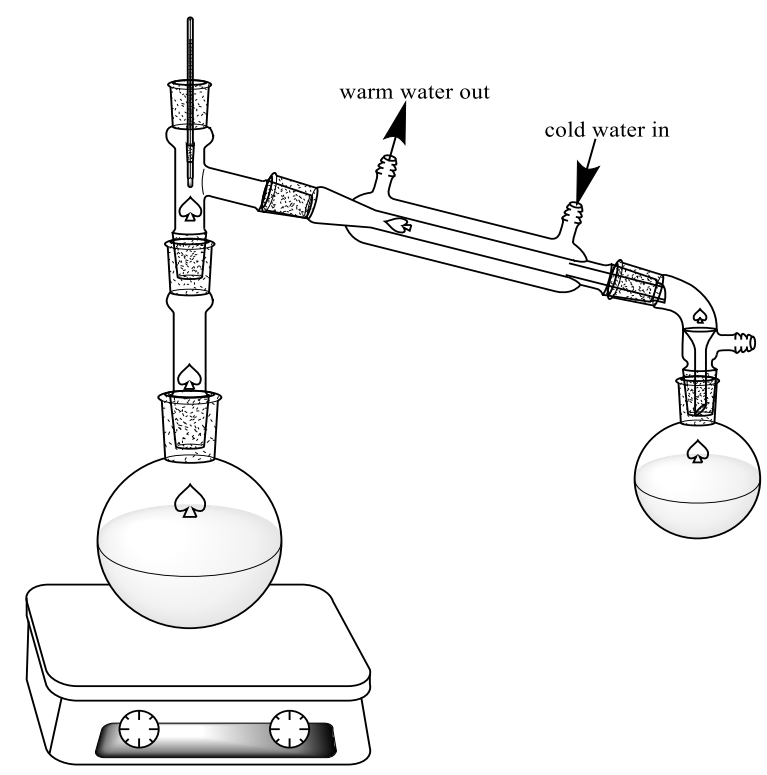

Figure S1. The distillation set-up for separating biocrude oil 
